\title{
Adubação fosfatada no desenvolvimento de Hemerocallis fulva $\mathrm{L}$.
}

\section{Phosphorus fertilization on the development of Hemerocallis fulva $\mathrm{L}$.}

\author{
Yara Brito Chaim Jardim Rosa ${ }^{1 *}$; Eulene francisco da Silva ${ }^{2}$; \\ Kamila de Almeida Mônaco ${ }^{3}$; Simome Cândido Ensinass; \\ Edgard Jardim Rosa Junior ${ }^{1}$; Derek Brito Chaim Jardim Rosa ${ }^{4}$
}

\section{Resumo}

Em Latossolos argilosos do cerrado onde é alta a fixação de P, a adubação fosfatada torna-se necessária para garantir o crescimento e florescimento de plantas ornamentais. Assim, esse estudo objetivou analisar o desenvolvimento de hemerocale em função da adubação fosfatada em Latassolo Vermelho Distroférrico. O experimento foi conduzido na área de Jardinocultura da Universidade Federal da Grande Dourados (UFGD) em Dourados - MS. O delineamento experimental utilizado foi em blocos casualizados, com quatro repetições. Os tratamentos consistiram de quatro doses de $\mathrm{P}_{2} \mathrm{O}_{5}(0 ; 250 ; 500$; $1000 \mathrm{~kg} \mathrm{ha}^{-1}$ ) utilizando como fonte superfosfato simples. A unidade experimental foi composta por uma planta de Hemerocallis fulva 'Flore Pleno', cultivada em vaso plástico com capacidade para cinco litros. A adubação fosfatada aumentou linearmente os teores de fósforo no solo e a planta obteve a sua máxima absorção $\left(5,26 \mathrm{~g} \mathrm{~kg}^{-1}\right)$ com a dose calculada de $727 \mathrm{~kg} \mathrm{ha}^{-1}$ de $\mathrm{P}_{2} \mathrm{O}_{5}$. A H. fulva possui sistema radicular que melhor se desenvolve sob alta disponibilidade de $\mathrm{P}$, no entanto para parte aérea, o máximo de massa fresca da parte aérea $(451,1 \mathrm{~g})$ foi obtido com $427 \mathrm{~kg} \mathrm{ha}^{-1}$ de $\mathrm{P}_{2} \mathrm{O}_{5}$. O número de botões florais, o diâmetro floral e altura da haste floral foram maiores na presença de fósforo.

Palavras-chave: Herbáceas perenes, fósforo, floricultura

\begin{abstract}
In clayey Oxisol from the Brazilian Cerrado, where there is high P fixation, the phosphorus fertilization is necessary to increase the growth and flowering of ornamental plants. Thus, the objective of this study was to analyze the development of Hemerocallis as affected by phosphorus application in clayey Oxisol (Typic Haplustox). The experiment was conducted at the Gardening area of University Federal of Grande Dourados (UFGD) in Dourados-MS, Brazil. The experimental design was a randomized block with four replications. The treatments consisted of four $\mathrm{P}_{2} \mathrm{O}_{5}$ rates $\left(0,250,500,1000 \mathrm{~kg} \mathrm{ha}^{-1}\right)$ using simple superphosphate as source. The experimental unit was composed of one Hemerocallis fulva 'Flore Pleno' plant, grown in a plastic pot (5 liters). Phosphorus fertilization increased linearly the concentration of phosphorus in the soil; the plant had maximum absorption $\left(5.26 \mathrm{~g} \mathrm{~kg}^{-1}\right)$ with the calculated dose of $727 \mathrm{~kg} \mathrm{ha}^{-1} \mathrm{P}_{2} \mathrm{O}_{5}$. H. fulva has a root system that develops best under high availability of $\mathrm{P}$, however, for aerial part, the maximum of shoots fresh mass (451.1 g) was obtained with $427 \mathrm{~kg} \mathrm{ha}^{-1}$ of $\mathrm{P}_{2} \mathrm{O}_{5}$. Number of flower buds, flower diameter and height flower stalks were higher in the presence of phosphorus.
\end{abstract}

Key words: Herbaceous perennial, phosphorus, floriculture

${ }^{1}$ Profs. da Faculdade de Ciências Agrárias, FCA, Universidade Federal da Grande Dourados, UFGD, Dourados, MS. E-mail: yararosa@ufgd.edu.br; edgardjunior@ufgd.edu.br

2 Prof $^{\mathrm{a}}$ do Dept ${ }^{\mathrm{O}}$ de Ciências Ambientais e Tecnológicas, DCAT, da Universidade Federal Rural do Semi-Árido, UFERSA, MossoróRN. E-mail: eulene_silva@yahoo.com.br

${ }^{3}$ Discente do Programa de Pós-Graduação em Agronomia-Horticultura, da Faculdade de Ciências Agronômicas da Universidade Estadual Paulista "Júlio de Mesquita”, UBESP, Botucatu, SP. E-mail: kamila_monaco@hotmail.com

${ }^{4}$ Discentes do Programa de Pós-Graduação em Agronomia-Produção Vegetal, FCA, UFGD, Dourados, MS. E-mail: simone_ candido@hotmail.com; derek_jardim@hotmail.com

* Autor para correspondência 
A diversidade de climas e solos no Brasil permite cultivos de inúmeras espécies de flores e plantas ornamentais, de diferentes origens (KIYUNA et al., 2004). Entre as plantas floríferas atualmente cultivadas, o gênero Hemerocallis (plantas perenes, herbáceas e eretas), ocupa lugar de destaque, com grande variedade de tipos e cores de flores, sendo conhecido no Brasil como lírio-de-são-josé, líriode-um-dia e lírio-amarelo. Entre os povos asiáticos, a planta é também usada na culinária, uma vez que suas flores são digestivas e nutritivas; os caules e raízes também são usados como analgésicos (TOMBOLATO, 2004).

Em relação à correção do solo e adubação, principalmente fosfatada, com espécies herbáceas perenes, como é o caso de Hemerocallis a literatura é muito escassa. Tombolato (2004) sugere que o $\mathrm{pH}$ ideal esteja entre 5,5 a 7,0, e em termos nutricionais salienta que o fósforo é essencial no início da floração e durante a primavera, promovendo vigor à planta e estimulando o crescimento radicular precoce. Com relação à adubação, não há uma recomendação especifica quanto à dosagem de $\mathrm{P}, \mathrm{N}$ ou $\mathrm{K}$ isoladamente. A literatura sugere que ela deva ser feita duas vezes por ano, embora não exista recomendação específica de um fertilizante. Geralmente recomenda-se adubo formulado completo como NPK (4-14-8, 10-10-10) ou em mistura com adubo orgânico (LONGHI; CASTRO; GONÇALVES, 1992, TOMBOLATO, 2004). Isto deve ser levado em consideração uma vez que, a adubação excessiva dessas plantas causa, além de um crescimento vegetativo exagerado, a diminuição do número de flores (ERHARDT, 1992).

$\mathrm{O}$ hemerocale se desenvolve em praticamente qualquer tipo de solo (do arenoso ao argiloso), mas de preferência, deve-se cultivá-lo em solo arenoargiloso. Devido ao aumento da demanda de flores e de plantas ornamentais, nos mercados interno e externo, está ocorrendo expansão do cultivo de flores também no Cerrado onde predominam os Latossolos argilosos. Esses solos geralmente são muito deficientes em $\mathrm{P}$ e, devido ao $\mathrm{pH}$ ácido e predominância de argilas sesquioxídicas, a fixação de fosfatos e precipitação por Fe e Al são altas, reduzindo drasticamente a disponibilidade e o aproveitamento pelas plantas do $\mathrm{P}$ aplicado (NOVAIS; SMITH, 1999). Estima-se que apenas $5 \%$ a $25 \%$ do fósforo solúvel adicionado ao solo, como adubo, seja aproveitado pela cultura que o recebeu, ou seja, entre $95 \%$ a $75 \%$ dele seja fixado (FALCÃO; SILVA, 2004). Portanto, este trabalho teve por objetivo avaliar a quantidade e qualidade de produção de flores de hemerocale em função da adubação fosfatada em Latossolo Vermelho Distroférrico no município de Dourados-MS.

Para isso, desenvolveu-se um experimento na área de Jardinocultura, da Faculdade de Ciências Agrárias (FCA) na Universidade Federal da Grande Dourados (UFGD), em Dourados-MS, nas coordenadas de $22^{\circ} 11^{\prime} 45^{\prime \prime} \mathrm{S}$ e $54^{\circ} 55^{\prime} 18^{\prime \prime} \mathrm{W}$, com altitude de $446 \mathrm{~m}$, de setembro de 2007 a março de 2009. O clima é do tipo Cwa mesotérmico úmido, a precipitação média anual é de $1500 \mathrm{~mm}$ e a temperatura média de $22^{\circ} \mathrm{C}$.

O delineamento experimental utilizado foi em blocos casualizados com, quatro repetições. Os tratamentos consistiram de quatro doses de $\mathrm{P}_{2} \mathrm{O}_{5}$ correspondentes a $0 ; 250 ; 500 ; 1000 \mathrm{~kg}$ ha ${ }^{1}$, utilizando como fonte superfosfato simples. A unidade experimental foi composta por uma planta de Hemerocallis fulva 'Flore Pleno', cultivada em vaso plástico com capacidade para cinco litros e todos os tratamentos receberam também $250 \mathrm{~kg} \mathrm{ha}^{-1}$ de $\mathrm{N}$, e $200 \mathrm{~kg} \mathrm{ha}^{-1} \mathrm{de}_{2} \mathrm{O}$, utilizando-se como fonte a uréia e o cloreto de potássio, respectivamente.

O solo utilizado para enchimento dos vasos foi proveniente de uma área de vegetação nativa, coletado na profundidade de 0-20 cm, e classificado como Latossolo Vermelho Distroférrico, cujos atributos químicos e físicos, analisados de acordo com Embrapa (1997) foram: $\mathrm{pH} \mathrm{CaCl}_{2}=4,2 ; \mathrm{P}=$ $2,0 \mathrm{mg} \mathrm{dm} 3{ }^{3} ; \mathrm{K}=0,4\left(\mathrm{mmol}_{\mathrm{c}} \mathrm{dm}^{3}\right) ; \mathrm{Al}=14,1\left(\mathrm{mmol}_{\mathrm{c}}\right.$ $\left.\mathrm{dm}^{3}\right) ; \mathrm{Ca}=4,0\left(\mathrm{mmol}_{\mathrm{c}} \mathrm{dm}^{3}\right) ; \mathrm{Mg}=3,0\left(\mathrm{mmol}_{\mathrm{c}} \mathrm{dm}^{3}\right)$; $\mathrm{H}+\mathrm{Al}=69,0\left(\mathrm{mmol}_{\mathrm{c}} \mathrm{dm}^{3}\right) ; \mathrm{SB}=7,4\left(\mathrm{mmol}_{\mathrm{c}} \mathrm{dm}^{3}\right) ; \mathrm{T}$ 
$=76,4\left(\mathrm{mmol}_{\mathrm{c}} \mathrm{dm}^{3}\right) ; \mathrm{V} \%=37$, areia $=17 \%$, silte $=$ $6,51 \%$ e argila $=76,49 \%$.

Para aumentar a saturação a $65 \%$ foram adicionados 4,2 $\mathrm{t} \mathrm{ha}^{-1}$ de $\mathrm{CaCO}_{3}$ calcítico, em toda amostra do solo, um mês antes do plantio. Após a homogeneização do solo com calcário, adicionouse quantidade de água de acordo com a capacidade máxima de retenção de água no solo (AWC), determinada pelo método do funil, que resultou em $30 \%$ do volume total do solo. Aos 31 dias decorridos da calagem foram adicionados, em cada vaso, $4,5 \mathrm{~kg}$ de solo sobre uma camada de drenagem de $2 \mathrm{~cm}$ de altura constituída por carvão vegetal lavado. Em cada vaso foi plantada uma muda de hemerocale, desprovida de parte aérea, a $10 \mathrm{~cm}$ de profundidade, de acordo com Tombolato (2004). As doses supracitadas de $\mathrm{P}_{2} \mathrm{O}_{5}$ e os $200 \mathrm{~kg} \mathrm{ha}^{-1}$ de $\mathrm{K}_{2} \mathrm{O}$ foram adicionadas no plantio, enquanto que os 250 $\mathrm{kg} \mathrm{ha}^{-1}$ de $\mathrm{N}$ foram parcelados $1 / 2$ no plantio e $1 / 2$ no inicio do florescimento.

Os vasos com as plantas foram acondicionados à meia sombra e receberam o equivalente a $500 \mathrm{~mL}$ de água $(50 \%$ da capacidade máxima de retenção de água do solo), divididos em duas aplicações semanais de $250 \mathrm{~mL}$ cada, para minimizar as perdas por evaporação, ocasião em que eram realizados controles manuais das plantas invasoras.

As características analisadas durante a condução do experimento foram: início do florescimento (número de dias após o plantio -DAP- para a emissão da haste floral), altura da haste floral (medida entre a superfície do solo e a inserção do botão floral basal), diâmetro das flores e número de botões florais. Dois meses após o término do florescimento, as plantas foram removidas do substrato, lavadas em água destilada separadas em parte aérea e sistema radicular, sendo quantificadas a massa fresca de cada uma destas partes. A seguir o solo de cada vaso foi passado em peneira de $2 \mathrm{~mm}$, seco à sombra (TFSA) e amostras de $200 \mathrm{~g}$ foram retiradas para análises laboratoriais dos teores de P determinado conforme Embrapa (1997), sendo extraídos com $\mathrm{HCl} \mathrm{0,05} \mathrm{mol} \mathrm{L-1}+\mathrm{H}_{2} \mathrm{SO}_{4} 0,0125 \mathrm{~mol}$ $\mathrm{L}^{-1}$ (Mehlich-1), e quantificado colorimétricamente. Toda a parte aérea vegetal colhida foi seca em estufa com circulação de ar forçada $\left(65^{\circ} \mathrm{C}\right)$, moída em moinho tipo wiley, e submetida à mineralização nítrico-perclórica, para dosagem colorimétrica do fósforo segundo metodologia de Braga e Defelipo (1974).

Os dados foram submetidos à análise de variância, e posteriormente à análise de regressão com uso do aplicativo SISVAR 5.3 e, para confecção dos gráficos o Sigma Plot 9.0.

Como resultados, observou-se que as doses de fósforo tiveram efeito significativo, ao nível de $1 \%$ de probabilidade, sobre o início do florescimento, altura da haste floral e diâmetro das flores e, ao nível de $5 \%$ de probabilidade, sobre o número de botões florais, massa seca da parte aérea e do sistema radicular e sobre os níveis de fósforo no solo e na parte aérea do vegetal.

A floração de hemerocale teve início em novembro de 2008, se estendendo até meados de janeiro de 2009, nas condições de Dourados - MS. Tombolato (2004) relata que na região Sul e Sudeste do Brasil o florescimento ocorre em outubro prolongando-se até o inicio de abril. Neste contexto, pode-se observar que no CentroOeste o período o florescimento do hemerocale é reduzido, atribuído certamente ao fato desta ser planta de dia longo, ou seja, floresce apenas quando submetida a horas de luz superiores ao fotoperíodo crítico (TAIZ; ZEIGER, 2004). Neste experimento, constatou-se que o início do florescimento também é afetado significativamente por diferentes doses de adubação fosfatada. Plantas de hemerocale quando não adubadas com fósforo floresceram aos 403 dias após o plantio, no entanto, quando submetidas à dose calculada de $539 \mathrm{~kg} \mathrm{ha}^{-1}$ de $\mathrm{P}_{2} \mathrm{O}_{5}$ iniciaram o florescimento mais tardio aos 415 dias (ponto de máximo), decrescendo esse período com o aumento da adubação, chegando a 406 dias na maior dose estudada (1.000 kg ha-1 de $\mathrm{P}_{2} \mathrm{O}_{5}$ ) (Figura 1a). 
Figura 1. Inicio do florescimento (a), número de botões florais (b), diâmetro floral (c) altura da haste floral (d), massa fresca do sistema radicular (e) e massa fresca da parte aérea de (f) de Hemerocallis fulva 'Flore Pleno', em função da adubação fosfatada. Dourados-MS, UFGD, 2009.
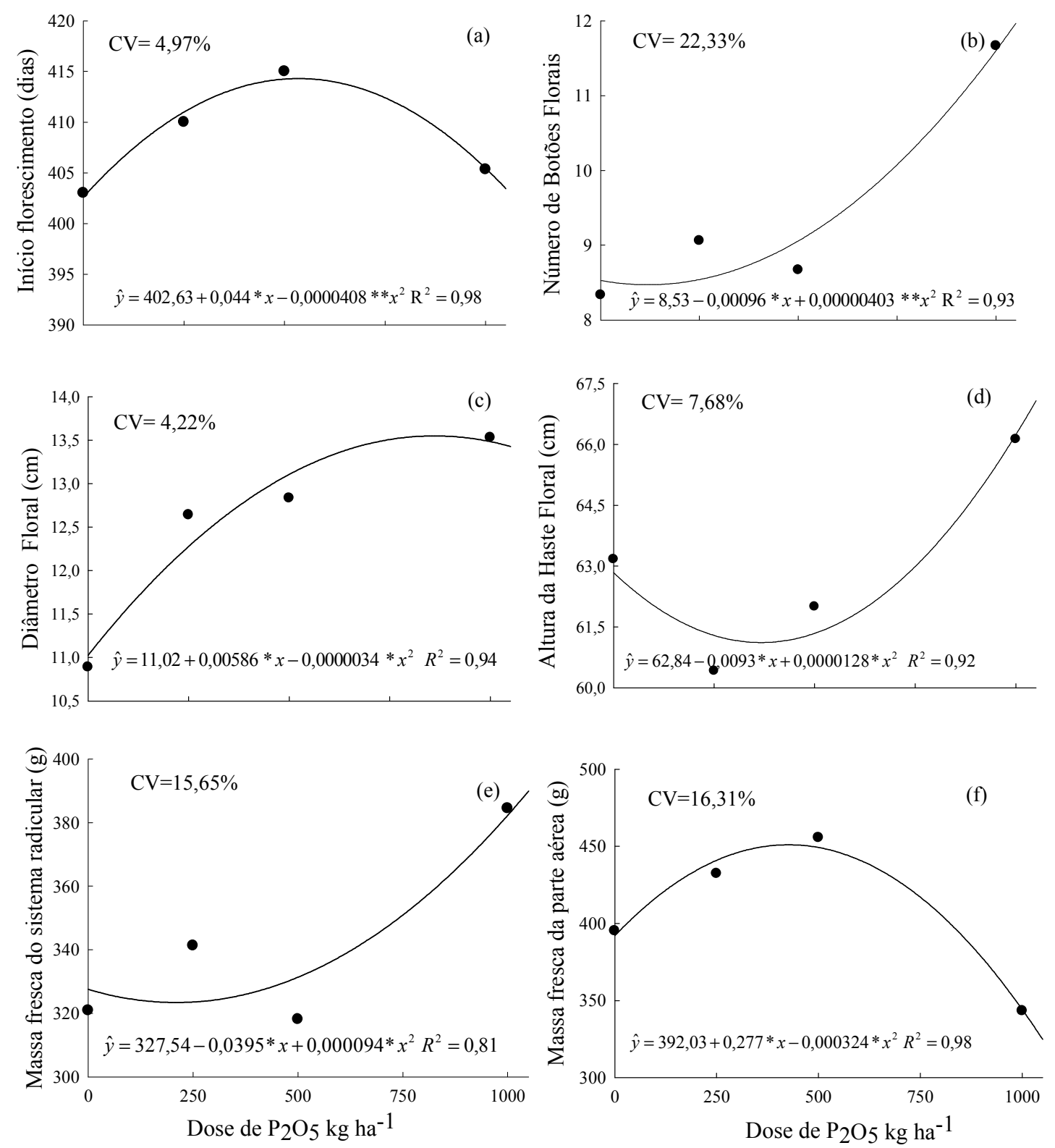

Fonte: Elaboração dos autores.

Com relação ao número de botões florais houve um aumento significativo a partir da dose de 119 $\mathrm{kg} \mathrm{ha}^{-1}$ de $\mathrm{P}_{2} \mathrm{O}_{5}$ obtendo o máximo de 12 botões florais por haste floral com $1000 \mathrm{~kg} \mathrm{ha}^{-1}$ (Figura 1 b). Entretanto, o diâmetro floral máximo $(13,5 \mathrm{~cm})$ foi atingido com $861,8 \mathrm{~kg} \mathrm{ha}^{-1}$ de $\mathrm{P}_{2} \mathrm{O}_{5}$ (Figura 1 c), corroborando aos relatos de Tombolato (2004) para Hemerocallis, de que o fósforo é essencial no início da florada, e com os de Freitas et al. (1999) que constataram que a adição ao substrato de 3,0g de $\mathrm{P}_{2} \mathrm{O}_{5}$ por planta, com adubações em cobertura com salitre duplo potássico a cada 20 dias, 
proporcionaram a obtenção de um número maior de flores da primeira haste floral em H. liliaphodellus.

Por ser uma planta muito utilizada em paisagismo é importante que suas hastes florais sejam altas e rígidas. Todas as hastes, independentemente da adubação, estiveram acima de $60 \mathrm{~cm}$, tendo alturas maiores a partir de $363 \mathrm{~kg} \mathrm{ha}^{-1}$ de $\mathrm{P}_{2} \mathrm{O}_{5}$ (Figura $1 \mathrm{~d}$ ). $\mathrm{O}$ efeito do fósforo sobre a altura da haste se explica pelo fato de ser um nutriente envolvido diretamente nos processos metabólicos das plantas, seja como fornecedor de energia, e/ou como componente de inúmeros complexos protéicos (MALAVOLTA; VITTI; OLIVEIRA, 1997). Efeito benéfico do fósforo em conjunto com o nitrogênio foi também observado por Chaturvedi, Shukla e Pandey (1991) no comprimento da haste floral de $H$. fulva L..

A adubação fosfatada também teve efeito sobre as produções de massa fresca radicular e da parte aérea de H. fulva 'Flore Pleno', embora o padrão de enraizamento esteja sob controle genético, o crescimento das raízes foi positivamente modificado a partir da dose calculada de $210,1 \mathrm{~kg} \mathrm{ha}^{-1}$ de $\mathrm{P}_{2} \mathrm{O}_{5}$ (ponto de mínimo) (Figura 1 e).

Em diversas culturas tem sido demonstrado que o P exerce grande influência sob o crescimento radicular. Estudos desenvolvidos por Klepker e Anghinoni (1996) permitem inferir que quanto maior o crescimento de raízes de milho, tanto em massa como em comprimento, tanto maior é a disponibilidade de $\mathrm{P}$ para as plantas. Para Otani e Ae (1996) a interação fósforo e planta é fortemente correlacionada com o comprimento das raízes em solos com elevado teor de fósforo disponível.

Da mesma forma, Lima et al. (2011) observaram que o fertilizante fosfatado também favoreceu o crescimento de mudas de pinhão-manso, principalmente de raízes e área foliar, e propiciou aumento do teor de todos os macronutrientes no tecido vegetal, exceto o cálcio. Já Prates et al. (2012) constataram que a matéria fresca da raiz, matéria fresca da parte aérea e matéria fresca total do pinhãomanso aumentaram linearmente até a dose de $10 \mathrm{~kg}$ $\mathrm{m}^{-3}$ do substrato, ambos os experimentos utilizando como fonte o superfosfato simples. Para as mudas, a elevada concentração de $\mathrm{P}$ induz a formação de um sistema radicular mais longo e com raízes mais finas, que seriam eficientes na absorção de outros nutrientes (KNAPIK, 2005), porém, as doses ótimas variam de acordo com a espécie.

Para parte aérea, o máximo de massa fresca $(451,1 \mathrm{~g})$ foi produzida com $427 \mathrm{~kg} \mathrm{ha}^{-1}$ de $\mathrm{P}_{2} \mathrm{O}_{5}$ (Figura $1 \mathrm{f}$ ). Por ser uma planta ornamental e muito utilizada como forração, a massa fresca da parte aérea é quesito fundamental para comercialização e implantação da cultura, e doses superiores a 427 $\mathrm{kg} \mathrm{ha}^{-1}$ foram prejudiciais a essa característica. O fósforo é um elemento essencial ao aumento da massa fresca das plantas, uma vez que, está envolvido na maioria dos processos metabólicos, no requerimento de energia, nos processos enzimáticos e no transporte de carboidratos (TAIZ; ZEIGER, 2004). Neste trabalho, em nenhuma das doses utilizadas foi observado sintomas visuais de deficiência ou toxidez deste nutriente.

A adubação fosfatada proporcionou acréscimo linear significativo nos teores de fósforo no solo até a dosagem de $1000 \mathrm{~kg} \mathrm{ha}^{-1} \mathrm{P}_{2} \mathrm{O}_{5}$, entretanto, na planta de hemerocale a máxima absorção de fósforo $(5,26$ $\mathrm{g} \mathrm{kg}^{-1}$ ) foi obtida com a dose calculada de $727 \mathrm{~kg} \mathrm{ha}^{-1}$ de $\mathrm{P}_{2} \mathrm{O}_{5}$ (Figura $2 \mathrm{a}, \mathrm{b}$ ). Assim, para o hemerocale não se recomendam adubações fosfatadas inferiores a $250 \mathrm{~kg} \mathrm{ha}^{-1}$, uma vez que, abaixo destes teores houve respostas lineares à absorção deste nutriente. Todavia, sob doses superiores a $727 \mathrm{~kg} \mathrm{ha}^{-1}$ não houve aumento do teor de P na planta (Figura 2 b), mas decréscimo. 
Figura 2. Teor de fósforo no solo (a) e na parte aérea das plantas de Hemerocallis fulva 'Flore Pleno'(b) em função da adubação fosfatada. Dourados-MS UFGD, 2009.
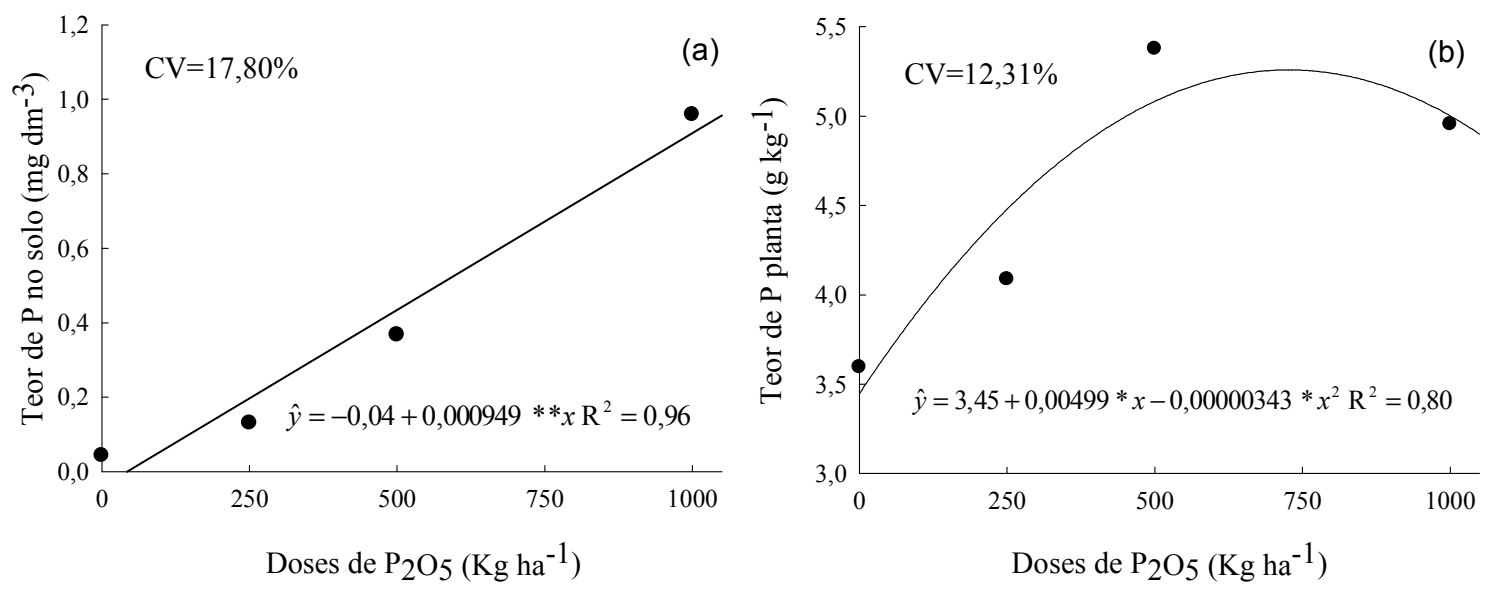

Fonte: Elaboração dos autores.

Em Latossolos, onde os solos são ácidos e se comportam como drenos, a concentração do P na solução do solo é de importância primária para o seu suprimento à raiz. Os resultados obtidos neste trabalho corroboram com relatos científicos de que, em solos intemperizados, quando a concentração deste nutriente aumenta na solução do solo, a absorção cresce rapidamente no princípio e depois tende a ficar constante em concentrações mais altas, tendendo para um valor máximo assintótico, podendo ocorrer um efeito desfavorável, ou até tóxico, em concentrações excessivas (MALAVOLTA, VITTI; OLIVEIRA, 1997, NOVAIS; SMYTH, 1999).

Nas condições em que foi conduzido esse experimento pode-se concluir que para Hemerocallis fulva "Flore pleno" doses crescentes de adubação fosfatada afetam positiva e diferencialmente os fatores relacionados à floração como: número de botões florais, diâmetro floral e altura da haste floral. O sistema radicular das plantas se desenvolve melhor sob alta disponibilidade de $\mathrm{P}$, no entanto para parte aérea, o máximo de produção de massa fresca ocorre com $427 \mathrm{~kg} \mathrm{ha}^{-1}$ de $\mathrm{P}_{2} \mathrm{O}_{5}$.

\section{Referências}

BRAGA, J. M.; DEFELIPO, B. V. Determinação espectofotométrica de fósforo em extratos de solos e planta. Revista Ceres, Viçosa, v. 21, n. 113, p. 73-85, 1974.

CHATURVEDI, O. P.; SHUKLA, H. S.; PANDEY, K. S. Response of daylily (Hemerocallis fulva L.) to nitrogen and phosphorus fertilization. Haryana Journal of Horticultural Sciences, Hisar, v. 20, n. 1-2, p. 77-80, 1991.

EMPRESA BRASILEIRA DE PESQUISA AGROPECUÁRIA- EMBRAPA. Manual de métodos de análises de solo. Rio de Janeiro: MAPA, 1997. 212 p.

ERHARDT, W. Hemerocallis: daylilies. Portland: Timber Press, 1992. 160 p.

FALCÃO, N. P. S.; SILVA, J. R. A. Características de adsorção de fósforo em alguns solos da Amazônia Central. Acta Amazônica, Manaus, v. 34, n. 3, p. 337342, 2004.

FREITAS, S. A. C.; CARVALHO, J. G.; COELHO, S. J.; SILVA, C. R. R. Efeito da adubação fosfatada no plantio e da aplicação em cobertura de salitre duplo potássico no lírio amarelo. Ciência e Agrotecnologia, Lavras, v. 23, n. 1, p. 79-83, 1999.

KIYUNA, I.; COELHO, P. J.; ÂNGElO, J. A.; ASSUMPÇÃO, R. Parceiros comerciais internacionais da floricultura brasileira. Informações Econômicas, São Paulo, v. 34, n. 5, p. 1-28, 2004. 
KLEPKER, D.; ANGHINONI, I. Crescimento radicular e aéreo do milho em vasos em função do nível de fósforo e localização do adubo fosfatado. Revista Brasileira de Ciência do Solo, Viçosa, v. 19, n. 3, p. 403-408, 1996.

KNAPIK, J. G. Utilização do Pó de basalto como alternativa à adubação convencional na produção de mudas de mimosa scabrella BENTH e Prunus sellowii KOEHNE. 2005. Dissertação (Mestrado em Ciências Florestais) - Universidade Federal do Paraná, Curitiba.

LIMA, R. L. S.; SEVERINO, L. S.; GHEYI, H. R.; SOFIATTI, V.; ARRIEL, H. C. Efeito da adubação fosfatada sobre o crescimento e teor de macronutrientes de mudas de pinhão manso. Revista Ciência Agronômica, Fortaleza, v. 42, n. 4, p. 950-956, 2011.

LONGHI, A. A.; CASTRO, C. E. F.; GONÇALVES, A. L. Hemerocallis. In: SIMPÓSIO BRASILEIRO DE FLORICULTURA E PLANTAS ORNAMENTAIS, 1., 1992, Maringá. Anais... Maringá: Sociedade Brasileira de Floricultura e Plantas Ornamentais, 1992. p. 232-235.
MALAVOLTA, E. A.; VITTI, G. C.; OLIVEIRA, A. S. Avaliação do estado nutricional das plantas: princípios e aplicações. Piracicaba: Potafós, 1997. 201 p.

NOVAIS, R. F.; SMYTH, T. J. Fósforo em solo e planta em condições tropicais. Viçosa: Universidade Federal de Viçosa, 1999. 399 p.

OTANI, T.; AE, N. Sensitivity of phosphorus uptake to chances in root length and soil volume. Agronomy Journal, Madison, v. 88, n. 3, p. 371-375, 1996.

PRATES, F. B. S.; LUCAS, C. S. G.; SAMPAIO, R. A.; BRANDÃO JÚNIOR, D. S.; FERNANDES, L. A.; ZUBA JUNIOR, G. R. Crescimento de mudas de pinhãomanso em resposta a adubação com superfosfato simples e pó-de-rocha. Revista Ciência Agronômica, Fortaleza, v. 43, n. 2, p. 207-213, 2012.

TAIZ, L.; ZEIGER, E. Fisiologia vegetal. 3. ed. Porto Alegre: Artmet, 2004. 722 p.

TOMBOLATO, A. F. C. Cultivo comercial de plantas ornamentais. Campinas: Instituto Agronômico de Campinas, 2004. 211 p. 
